\title{
Hepato cellular carcinoma in sub-Saharan black African women
}

\begin{abstract}
Although the occurrence of hepato cellular carcinoma in Sub-Saharan Black African males has been reasonably fully documented relatively little information on the characteristics of the tumor in Black African females has hitherto been published. There has also been a tendency to under-estimate the occurrence of the tumor in this population. Nevertheless, the incidence of hepato cellular carcinoma in Black African women is appreciably lower than that in Black African men with an average incidence of 1.0:3.4. Black African women with his tumor are generally older than Black African men with hepato cellular carcinoma, with a mean age of 51.0years and a range of 16 to 80 years in comparison with a mean age of 33.4 years and $50 \%$ of the male patients being younger than $30 y$ years of age. The symptoms and physical signs of hepato cellular carcinoma do not differ significantly between females and males. Black African women have a similar rate of chronic hepatitis B virus infection as Black African men excluding this etiologic agent as the explanation for the lower rate of the tumor in women. Black women are as likely as Black men to develop hepatitis $\mathrm{C}$ virus and aflatoxin $\mathrm{B}_{1}$-induced hepato cellular carcinoma. However, dietary iron overload which plays an important role in the causation of the tumor in rural black African men plays a very much lesser role in Black African women.
\end{abstract}

Keywords: black women, sub-saharan Africa, relatively young age, older age than males, similar rates of hepatitis, hepatitis $b$ and $c$ virus infections
Volume 2 Issue 5 - 2016

\begin{abstract}
Michael C Kew
Department of Medicine, Groote Schuur Hospital, South Africa
\end{abstract}

Correspondence: Michael C Kew, Department of Medicine, Groote Schuur Hospital, Main Road, Observatory, Cape Town, South Africa,Tel 02 I-782 2949, Email michael.kew@uct.ac.za

Received: December 21, 2015 | Published: December 30, 2016
Abbreviations: HCC, hepato cellular carcinoma; HBV, hepatitis $b$ virus

\section{Introduction}

The high incidence of hepato cellular carcinoma (HCC) and the relatively young age at which the tumor frequently occurs in ruraldwelling to a lesser extent, urban-dwelling sub-Saharan Black African men, have been adequately documented. ${ }^{1}$ By contrast little information has been published on the incidence of $\mathrm{HCC}$ or on the characteristics of the tumor in sub-Saharan Black African women. As an indirect consequence there has been a tendency to assume that HCC occurs less often in sub-Saharan Black African women than it does in the male population. The majority of the relatively few Black African women who have been reported to have developed HCC have been urban-dwellers although most of these had spent their childhood and early adulthood in a rural environment before relocating to the cities..$^{1-3}$ The remainder of the women have been either De novo urban dwellers or have always been rural dwellers.

\section{Incidence of hepato cellular carcinoma}

Because of the many instances in which HCC in sub-Saharan Black African women living in rural areas are either not definitively diagnosed or if not recorded in a cancer registry the few published reports of the occurrence of the tumor significantly underestimated the true incidence of $\mathrm{HCC}$ in this population. The one exception may have been in Mozambique in southern Africa where the tumor in Black African women was reported to account for $31 \%$ of hepatic tumors. ${ }^{4}$ Since that time, however it has become evident that HCC does occur in Black women living in the African sub-continent with a significant incidence but one that is appreciably lower than that in Black African men the ratio ranging from 1.0:2.1 to 1.0:8.0 with an average ratio of
1.0:3.4 in the different published sera. ${ }^{1-3}$ Sub-Saharan Black African men and women have similar increased incidences of chronic hepatitis $\mathrm{B}$ virus (HBV) infection ${ }^{5-8}$ the major cause of $\mathrm{HCC}$ in this population. It is therefore unlikely that different rates of chronic infection with this virus are the explanation for the lower rate of HCC in Black African women. However, it is possible that lower exposure rates to other environmental hepato carcinogens may have contributed to the relatively low incidence of $\mathrm{HCC}$ as may differences in the rates and efficiency with which chemical hepato carcinogens such as aflatoxin $\mathrm{B}_{1}$ are metabolized.

\section{Age distribution}

Sub-Saharan Black African women with HCC are generally older than Black African men with the tumor. In early studies female patients ranged in age from 15 to 80years with a mean of age of 51.0years ${ }^{5-7}$ and in a more recent analysis these data were confirmed (ages ranged from 16 to 80 years) with a mean age of 50.2 years. At the time that the diagnosis of HCC was made in the more recent analysis $14.3 \%$ of the patients were younger than 30years of age and 35.7\% were older than 60years of age. By contrast, the mean age of rural Black African men with HCC was 34.7 years (range 10 to 61years) in one study ${ }^{5}$ and 33.4years in another. In the former of these two analyses $50 \%$ of the patients were younger than 30 years of age ${ }^{5}$ whereas the average age of the far fewer urban Black African males with HCC in the latter analysis was 50.9 years (range 10 to 78 years). $39 \%$ of the first group of female patients with HCC were of child-bearing age (range 15 to 49 years) ${ }^{5}$ and in the more recent analysis $41.6 \%$ were in this age- range. Black Africans who migrate in early adulthood from rural regions into the towns or cities in southern Africa develop $\mathrm{HCC}$ at an average age approximately 20years older than those who remain in a rural setting. ${ }^{6,7}$ This phenomenon has not been looked for (or at least been published) in the populations of other regions of the 
African sub-continent and may or may not occur in these regions. The presence of cirrhosis co-existing with HCC in sub-Saharan Black Africans does not influence the age of the female patients: $59.7 \%$ of those less than 30years of age and $63.8 \%$ of those 50years of age or older have co-existing cirrhosis. ${ }^{6}$

\section{Gender distribution}

In all populations studied women have had a lower incidence of HCC than have men. In this respect male predominance is even greater in Black African populations. The mean ratio of the occurrence of HCC in Black African women in comparison with healthy female controls ranges in different published series from 2.1:1.0 to 5.7:1.0 with an average ratio of 3.5:1.0. ${ }^{8-12}$ When age-related the ratios are 8.1:1.0 in women less than 30years of age and 4.2:1.0 in women older than 50years of age..$^{8-12}$ The reason or reasons for the difference in the incidence of HCC in Black African females and males has not been fully investigated and remains unexplained.

\section{Tribal distribution}

The majority of Black African women who have been documented, by proportional frequencies, to develop HCC are Sothos (29.2), Zulus (27.7), Gambians (19.1), Malawians (15.1), Tswanas (10.8\%) and Camaroonians (10.3).

\section{Symptoms and physical signs}

The symptoms and signs of HCC in female patients are generally not different from those in male patients. Significantly fewer Black African females than males with HCC (9.4\% cf. $26.7 \%)$ give a history of symptoms of shorter than two weeks duration although symptoms of longer than two but shorter than four weeks are equally common in the two sexes $\left(33.3 \%\right.$ for females, $34.1 \%$ for males). ${ }^{1}$ Symptoms of longer than four but shorter than 8 weeks duration are slightly less common in females than males ( 9.4 for females $\mathrm{cf}$. 13.7 for males) but those of longer than 8 but shorter than 12 weeks duration are significantly less common in females (10.4 for females, 27.4 for males).$^{1,11-13}$ Upper abdominal pain is an almost invariable symptom in women with HCC. ${ }^{15,16}$ The pain is typically of short duration and is felt in the right hypochondrium, epigastrium or right lower chest region and becomes more severe with the continued growth of the tumor and hence distension of the hepatic capsule. ${ }^{15,16}$ Many patients also become aware of an PPER abdominal mass over time. ${ }^{15,16}$ Weakness and malaise are common complaints, as is loss of weight ${ }^{15,16}$ the last-mentioned perhaps being of lesser degree in females than in males. Hepatomegaly is an almost invariable physical finding. The tumorous liver is always firm and may be rock-hard it is typically tender. A bruit is heard over the tumor in approximately one-quarter of patients. ${ }^{14}$ Ascites is present in approximately one-half of the patients. Slight or moderate muscle wasting is almost invariable and jaundice is present in between 21 and $40 \%$ of the patients. ${ }^{14} \mathrm{~A}$ skin rash (Pityriasis rotunda) is occasionally present.

\section{Diagnosis}

In the majority of Black African female patients as in patients of other races the diagnosis of $\mathrm{HCC}$ is made or suspected on the basis of the clinical and radiological findings and supported in the first instance by a diagnostically raised serum $\alpha$-fetoprotein level. The latter is present in approximately $60 \%$ of Black African females with HCC. ${ }^{15}$ In the great majority of Black African women with HCC the diagnosis has been confirmed by percutaneous biopsy and in $12.5 \%$ of the patients the diagnosis is made only at necropsy. The highly efficient organ-imaging facilities now used in the diagnosis of HCC in many first world countries are not yet available in the rural hospitals of sub-Saharan Africa or in the hospitals in the smaller cities or towns.

\section{Etiology}

The causes of HCC in sub-Saharan Black African women do not differ from those in men although the relative frequency with which the causes may occur may differ.

\section{Hepatitis B virus infection}

Hepatitis B virus (HBV) was among the first viruses to be causally linked to a human cancer and it is now recognized to be the predominant risk factor for HCC world- wide. Black African women infected with the virus are as likely as men to develop HCC. Approximately $30 \%$ of the Black African women with HCC have HBs antigenemia, 16\% are anti-HBs positive alone and $81 \%$ have been infected with the virus at one time or another. ${ }^{7}$ The association is closest in young patients, with $45 \%$ of the women less than 40 years of age being positive for HBs Ag and another approximately $25 \%$ positive for anti-HBc alone. ${ }^{7}$ Approximately $81 \%$ of Black African women with HCC have been infected with $\mathrm{HBV}$ at one time or another ${ }^{7}$ and the rate of $\mathrm{HBV}$ infection in Black African females is approximately one-half the rate of infection in Black males. ${ }^{7}$ The prevalence of HBs antigenemia decreases with increasing age of the female patients with HCC.

\section{Aflatoxin B,}

Aflatoxin $\mathrm{B}_{1}$ plays an important role in the pathogenesis of HCC in tropical and sub-tropical climates of sub-Saharan Africa. ${ }^{18}$ Rural dwelling men and women are equally likely to be affected. Certain staple foodstuffs such as maize and ground nuts are prone to contamination by these fungi. Contamination of crops takes place both during the growth of the crops and as a result of their improper storage. Aflatoxin $\mathrm{B}_{1}$ is converted into aflatoxin $\mathrm{B}_{1}-8,9$ exo-epoxide which in turn is converted into 8,9- dihydroxy-8-(N7) guanyl-9hydroxy aflatoxin $\mathrm{B}_{1}$ adduct which is metabolized into aflatoxin $\mathrm{B}_{1}$ formaminopyrimidine adduct. These adducts are mutagenic and carcinogenic. In addition an arginine to serine mutation at codon 249 of the p53 tumor suppressor gene is produced which contributes to the hepato carcinogenesis. ${ }^{18}$

\section{Hepatitis $\mathbf{C}$ virus infection}

Hepatitis $\mathrm{C}$ virus (HCV) plays a lesser role than HBV in causing HCC in sub-Saharan Black African women than does HBV. One exception is in Somalia where the two viruses appear to play equal roles, accounting between them for approximately $70 \%$ of the HCCs. The overall percentage of patients in sub-Saharan Africa who are positive for $\mathrm{HCV}$ range from $6.2 \%$ to $40 \%$ with a relative risk of the tumor developing of 5.7 to $27.2 .{ }^{19}$ However, relatively little has been published on the exact risk of HCV-induced HCC developing in Black African women, or on the mechanisms involved.

\section{Dietary iron overload in the sub-saharan black African}

This not infrequent cause of HCC in sub-Saharan Black African males plays a small role only in causing the tumor in females. ${ }^{20}$ Although rural Black African females are responsible for brewing the iron-rich beer in rural regions of the sub-continent the women who drink the iron-rich product are protected to an extent from developing iron overload because they consume smaller volumes of the iron-rich beer than the males and they lose iron from the body in menstrual blood and as a result of child-bearing. 


\section{Membranous obstruction of the inferior vena cava}

Although membranous obstruction of the inferior vena cava occurs equally often in Black males and females, HCC complicating the condition is 2.5 times more common in males. ${ }^{19}$ Little is known about the etiology and pathogenesis of HCC in this condition in the Black African population.

\section{Diagnosis, prognosis and treatment}

No significant differences exist in the diagnosis, management and prognosis of $\mathrm{HCC}$ in Black African women with $\mathrm{HCC}$ in comparison with Black African men with the tumor.

\section{Acknowledgements}

None.

\section{Conflict of interest}

Author declares that there is no conflict of interest.

\section{References}

1. Kew MC. Hepatocellular carcinoma in sub-Saharan Africa. Bloomington, USA: Trafford Publishing; 2012. 1-37p.

2. John Higginson. The epidemiology of primary carcinoma of the liver. In: Pack GT, Islam AH, editors. Tumors of the liver. USA: Springer Berlin Heidelberg; 1970;26:38-52.

3. Hutt MSR. Epidemiology of human primary liver cancer. Lyon: IARC Scientific Publications; 1970;1:21-29.

4. Prates MD, Torres FO. A cancer survey in Lourenco Marques, Portugese East Africa. J Natl Cancer Inst. 1965;35(5):729-757.

6. Kew MC, Rossouw E, Paterson A, et al. Hepatitis B virus status in Black women with hepatocellular carcinoma. Gastroenterology. 1983;84(4):693-696.

7. Prozesky OW, Szmuness W, Stevens CE, et al. Baseline epidemiological studies for a hepatitis B vaccine trial in Kangwane. S Afr Med J. 1983;64(23):891-893.
6. Kew MC. The possible etiologic role of hepatitis B virus in hepatocellular carcinoma. In: Chisari FV, editor. Evidence from southern Africa. New York, USA: Advances in Hepatitis Research, Masson Publishing; 1984. p. 203-215.

7. Kew MC, Macerollo P. The effect of age on the etiological role of the hepatitis B virus in hepatocellular carcinoma in Black Africans. Gastroenterology. 1988;94(2):439-442.

8. Pisani P, Bray F, Parkin DM. The prevalence of cancer for 25 sites in the adult population. Int J Cancer. 2002;97(1):72-81.

9. Parkin DM, Bray F, Ferlay J, et al. Global cancer statistics, 2002. CA Cancer J Clin. 2005;55(2):74-108.

10. Ferlay J, Shin HR, Bray F, et al. Estimates of worldwide burden of cancer in 2008: GLOBOCAN 2008. Int J Cancer. 2010;127(12):2893-2917.

11. Nguyen VT, Law MG, Dore GJ. Hepatitis B virus-related hepatocellular carcinomas: epidemiological characteristics and disease burden. J Viral Hepat. 2009;16(7):453-463.

12. Kew MC. Hepatocellular carcinoma in sub-Saharan Africa. USA: Trafford, Publishing; 2012. 28-32p.

13. Kew MC. Hepatocellular carcinoma in sub-Saharan Africa. USA: Trafford Publishing; 2012. 32-37p.

14. Kew M. Alpha-fetoprotein in primary liver cancer and other diseases. Gut. 1974;15(10):814-821.

15. Kew MC (2013) Aflatoxins as causes of hepatocellular carcinoma. $J$ Gastrointestin Liver Dis. 2013;22(3):305-310.

16. Kew MC. Hepatitis $\mathrm{C}$ virus and hepatocellular carcinoma in developing and developed countries. Vir hepatit Rev. 1998;4:259-269.

17. Mandishona E, MacPhail AP, Gordeuk VR, et al. Dietary iron overload as a risjk factor for hepatopcellular carcinoma in Black Africans. Hepatology. 1988;27(6):1563-1566.

18. Kew MC, Hodkinson HJ. Membranous Membranous obstruction of the inferior vena cava and its causal relation to hepatocellular carcinoma. Liver Int. 2006;26(1):1-7. 